Article

\title{
Echinohalimane A, a Bioactive Halimane-Type Diterpenoid from a Formosan Gorgonian Echinomuricea sp. (Plexauridae)
}

\section{Hsu-Ming Chung ${ }^{1,2}$, Li-Chung Hu ${ }^{2,3}$, Wei-Hsuan Yen ${ }^{2,3}$, Jui-Hsin Su ${ }^{1,2,3}$, Mei-Chin Lu ${ }^{2,3}$, Tsong-Long Hwang ${ }^{4}$, Wei-Hsien Wang ${ }^{1,2, *}$ and Ping-Jyun Sung ${ }^{1,2,3, *}$}

1 Department of Marine Biotechnology and Resources and Asia-Pacific Ocean Research Center, National Sun Yat-sen University, Kaohsiung 804, Taiwan;

E-Mails: shiuanmin@yahoo.com.tw (H.-M.C.); x2219@nmmba.gov.tw (J.-H.S.)

2 National Museum of Marine Biology and Aquarium, Pingtung 944, Taiwan;

E-Mails: stoja582@gmail.com (L.-C.H.); xyz78714@hotmail.com (W.-H.Y.); jinx6609@nmmba.gov.tw (M.-C.L.)

3 Graduate Institute of Marine Biotechnology and Department of Life Science and Institute of Biotechnology, National Dong Hwa University, Pingtung 944, Taiwan

4 Graduate Institute of Natural Products, Chang Gung University, Taoyuan 333, Taiwan; E-Mail: htl@mail.cgu.edu.tw

* Authors to whom correspondence should be addressed; E-Mails: whw@nmmba.gov.tw (W.-H.W.); pjsung@nmmba.gov.tw (P.-J.S.); Tel.: +886-8-882-5001 (ext. 5047) (W.-H.W.); +886-8-882-5037 (P.-J.S.); Fax: +886-8-882-4488 (W.-H.W.); +886-8-882-5037 (P.-J.S.).

Received: 5 September 2012; in revised form: 24 September 2012 / Accepted: 8 October 2012 / Published: 17 October 2012

\begin{abstract}
A new halimane-type diterpenoid, echinohalimane A (1), was isolated from a gorgonian, identified as Echinomuricea sp. The structure of $\mathbf{1}$ was determined by spectroscopic methods and this compound was found to exhibit cytotoxicity toward various tumor cells and display an inhibitory effect on the release of elastase by human neutrophils. Echinohalimane A (1) is the first halimane analogue from the marine organisms belonging to phylum Cnidaria.
\end{abstract}

Keywords: halimane; echinohalimane; Echinomuricea; cytotoxicity; elastase 


\section{Introduction}

The search for bioactive natural products from marine organisms has been remarkably successful [1] and octocorals have proven to be rich sources of interesting natural products [2,3]. In continuation of our search for new natural products from the marine invertebrates collected off the waters of Taiwan at the intersection of the Kuroshio current and the South China Sea surface current, a new bioactive substance, echinohalimane A (1) (Figure 1), was isolated from the gorgonian Echinomuricea sp. In this paper, we describe the isolation, structure determination and biological activities of echinohalimane A (1).

Figure 1. The structure of echinohalimane A (1).

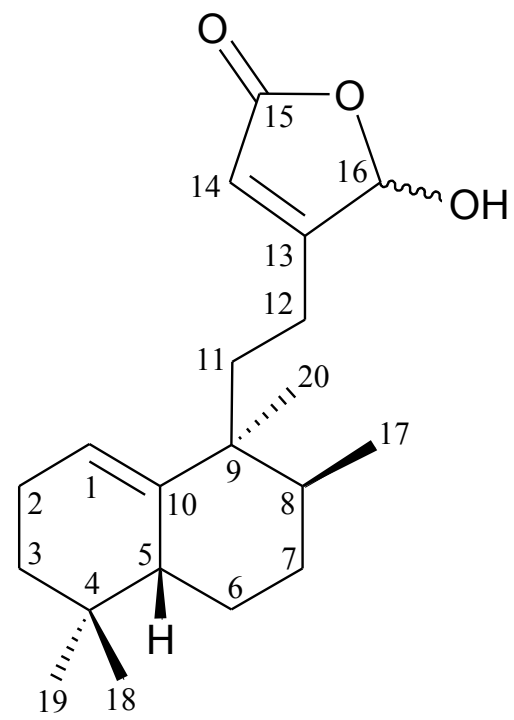

\section{Results and Discussion}

In previous studies, two bisabolane-type sesquiterpenoids, $(7 S, 10 R)-(+)-10,11$-epoxycurcuphenol and (+)-curcuphenol [4]; a labdane-type diterpenoid, echinolabdane A [5]; a clerodane-type diterpenoid, echinoclerodane A [6]; and a steroid analogue, 6-epi-yonarasterol B [5], had been isolated from a Formosan gorgonian coral identified as Echinomuricea sp. (Plexauridae). We have further isolated a new halimane-type diterpenoid, echinohalimane A (1), from Echinomuricea sp.

Echinohalimane A (1) was isolated as a yellowish oil that gave a pseudomolecular ion $(\mathrm{M}+\mathrm{Na})^{+}$at $m / z 341.2089$ in the HRESIMS, indicating the molecular formula $\mathrm{C}_{20} \mathrm{H}_{30} \mathrm{O}_{3}$ (calcd for $\mathrm{C}_{20} \mathrm{H}_{30} \mathrm{O}_{3}+\mathrm{Na}$, 341.2093) and implying six degrees of unsaturation. IR absorptions were observed at 3375 and $1755 \mathrm{~cm}^{-1}$, suggesting the presence of hydroxy and ester groups in $\mathbf{1}$. The ${ }^{13} \mathrm{C}$ NMR for $\mathbf{1}$ confirmed the presence of 20 carbon signals (Table 1), which were characterized by DEPT as four methyls, six $\mathrm{sp}^{3}$ methylenes, three $\mathrm{sp}^{3}$ methines, two $\mathrm{sp}^{2}$ methines, two $\mathrm{sp}^{3}$ quaternary carbons and three $\mathrm{sp}^{2}$ quaternary carbons. A suite of resonances at $\delta_{\mathrm{C}} 172.2$ (C-15), 171.6 (C-13), 116.7 (CH-14) and 99.4 $(\mathrm{CH}-16)$, could be assigned to an $\alpha, \beta$-unsaturated- $\gamma$-lactone moiety [6]. A trisubstituted olefin was deduced from the ${ }^{13} \mathrm{C}$ NMR data at $\delta_{\mathrm{C}} 145.0(\mathrm{C}-10)$ and $118.1(\mathrm{CH}-1)$. Thus, from the reported data, the proposed skeleton of 1 was suggested to be a diterpenoid with three rings. 
Table 1. ${ }^{1} \mathrm{H}\left(400 \mathrm{MHz}, \mathrm{CDCl}_{3}\right)$ and ${ }^{13} \mathrm{C}\left(100 \mathrm{MHz}, \mathrm{CDCl}_{3}\right) \mathrm{NMR}$ data, ${ }^{1} \mathrm{H}-{ }^{1} \mathrm{H} \mathrm{COSY}$ and HMBC correlations for diterpenoid 1.

\begin{tabular}{|c|c|c|c|c|}
\hline Position & $\delta_{\mathrm{H}}(J$ in $\mathrm{Hz})$ & $\delta_{\mathrm{C}}$, Multiple & ${ }^{1} \mathrm{H}_{-1}{ }^{1} \mathrm{H} \mathrm{COSY}$ & HMBC \\
\hline 1 & 5.40 br s & $118.1, \mathrm{CH}$ & $\mathrm{H}_{2}-2$ & $C-2,-9$ \\
\hline 2 & $2.02 \mathrm{~m}$ & 23.2, $\mathrm{CH}_{2}$ & $\mathrm{H}-1, \mathrm{H}_{2}-3$ & $C-1,-3,-4,-10$ \\
\hline 3 & $1.11 \mathrm{~m}, 1.28 \mathrm{~m}$ & $31.2, \mathrm{CH}_{2}$ & $\mathrm{H}_{2}-2$ & $C-2,-4,-18,-19$ \\
\hline 4 & & $31.2, \mathrm{C}$ & & \\
\hline 5 & 1.49 br d (14.8) & $43.7, \mathrm{CH}$ & $\mathrm{H}_{2}-6$ & $C-3,-4,-7,-10$ \\
\hline 6 & $1.09 \mathrm{~m}, 1.80 \mathrm{~m}$ & $30.0, \mathrm{CH}_{2}$ & $\mathrm{H}-5, \mathrm{H}_{2}-7$ & n.o. \\
\hline 7 & $1.42 \mathrm{~m}, 1.55 \mathrm{~m}$ & $31.1, \mathrm{CH}_{2}$ & $\mathrm{H}_{2}-6, \mathrm{H}-8$ & C-8, -9 \\
\hline 8 & $1.32 \mathrm{~m}$ & $44.3, \mathrm{CH}$ & $\mathrm{H}_{2}-7, \mathrm{H}_{3}-17$ & $C-7,-9,-10,-17$ \\
\hline 9 & & $42.5, \mathrm{C}$ & & \\
\hline 10 & & $145.0, \mathrm{C}$ & & \\
\hline 11 & $1.32 \mathrm{~m}, 1.90 \mathrm{~m}$ & $28.2, \mathrm{CH}_{2}$ & $\mathrm{H}_{2}-12$ & $C-10,-13,-20$ \\
\hline 12 & $2.10 \mathrm{~m}$ & $22.3, \mathrm{CH}_{2}$ & $\mathrm{H}_{2}-11$ & \\
\hline 13 & & 171.6, C & & \\
\hline 14 & $5.79 \mathrm{~s}$ & $116.7, \mathrm{CH}$ & & $C-13,-15,-16$ \\
\hline 15 & & $172.2, \mathrm{C}$ & & \\
\hline 16 & $5.98 \mathrm{~s}$ & $99.4, \mathrm{CH}$ & & $C-13,-14,-15$ \\
\hline 17 & $0.86 \mathrm{~d}(6.4)$ & $16.3, \mathrm{CH}_{3}$ & $\mathrm{H}-8$ & $C-7,-8,-9$ \\
\hline 18 & $0.85 \mathrm{~s}$ & 27.5, $\mathrm{CH}_{3}$ & & $C-3,-4,-5,-19$ \\
\hline 19 & $0.84 \mathrm{~s}$ & 27.7, $\mathrm{CH}_{3}$ & & $C-3,-4,-5,-18$ \\
\hline 20 & $1.04 \mathrm{~s}$ & $22.9, \mathrm{CH}_{3}$ & & $C-8,-9,-10,-11$ \\
\hline
\end{tabular}

Figure 2. The ${ }^{1} \mathrm{H}-{ }^{1} \mathrm{H}$ COSY and selective $\mathrm{HMBC}$ correlations (protons $\rightarrow$ quaternary carbons) for diterpenoid $\mathbf{1}$.

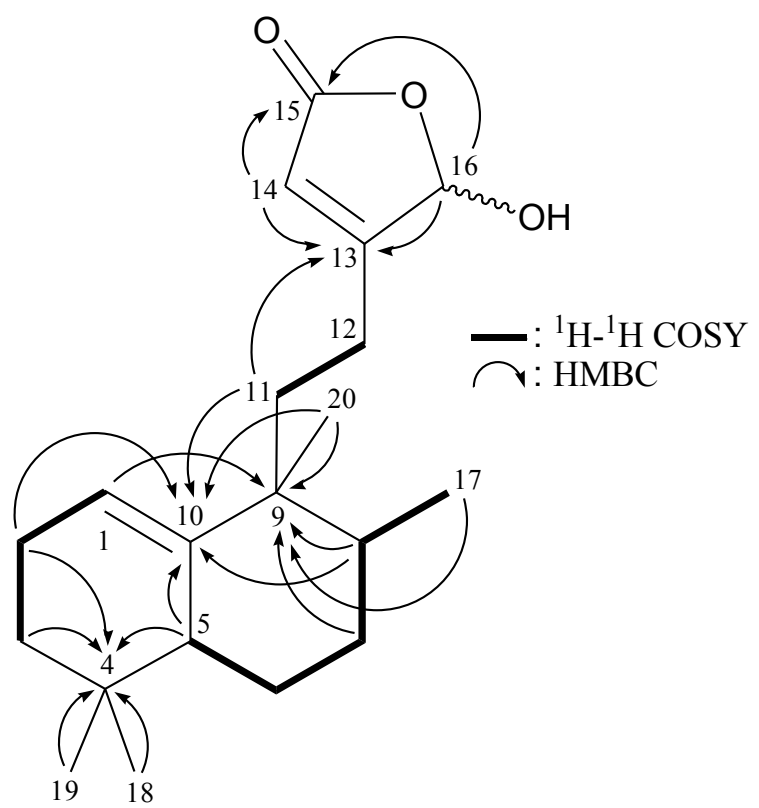

From the ${ }^{1} \mathrm{H}-{ }^{1} \mathrm{H}$ COSY experiment of $\mathbf{1}$ (Table 1 and Figure 2), it was possible to establish the spin systems that map out the proton sequences from $\mathrm{H}-1 / \mathrm{H}_{2}-2 / \mathrm{H}_{2}-3, \mathrm{H}-5 / \mathrm{H}_{2}-6 / \mathrm{H}_{2}-7 / \mathrm{H}-8 / \mathrm{H}_{3}-17$ and 
$\mathrm{H}_{2}-11 / \mathrm{H}_{2}-12$, which was accomplished with the assistance of an HMBC experiment (Table 1 and Figure 2). The key HMBC correlations between protons and quaternary carbons of $\mathbf{1}$, including $\mathrm{H}_{2}-2$,

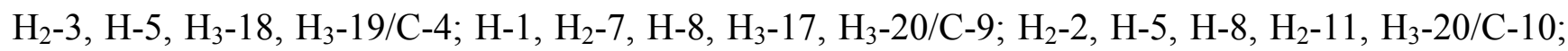
$\mathrm{H}_{2}-11, \mathrm{H}-14, \mathrm{H}-16 / \mathrm{C}-13$; and $\mathrm{H}-14, \mathrm{H}-16 / \mathrm{C}-15$, permitted the elucidation of the carbon skeleton of 1 . The tertiary methyls at C-4, C-8 and C-9 were confirmed by the HMBC correlations between $\mathrm{H}_{3}-18 / \mathrm{C}-3$, $-4,-5,-19 ; \mathrm{H}_{3}-19 / \mathrm{C}-3,-4,-5,-18 ; \mathrm{H}_{3}-17 / \mathrm{C}-7,-8,-9$; and $\mathrm{H}_{3}-20 / \mathrm{C}-8,-9,-10,-11$. The methine unit at $\delta_{\mathrm{C}} 99.4(\mathrm{CH}-16)$ was more shielded than that expected for an oxygenated $\mathrm{C}$-atom and correlated with the methine proton at $\delta_{\mathrm{H}} 5.98(\mathrm{H}-16)$ in the HMQC spectrum, and this proton showed ${ }^{3} J$-correlations with $\mathrm{C}-14$ and $\mathrm{C}-15$ in the HMBC spectrum and concluded to be a part of a hemiketal constellation.

The relative configuration of $\mathbf{1}$ was elucidated mainly from a NOESY spectrum as being compatible with that of 1 ascertained using molecular mechanics calculations (MM2), which suggested the most stable conformations, as shown in Figure 3 [7], in which the close contacts of atoms in space calculated were consistent the NOESY correlations. In the NOESY experiment of 1, H-5 exhibited correlations with $\mathrm{H}_{3}-17$ and a proton of $\mathrm{C}-11$ methylene $\left(\delta_{\mathrm{H}} 1.90\right)$, but not with $\mathrm{H}-8$ and $\mathrm{H}_{3}-20$, indicated that $\mathrm{H}-5$ and $\mathrm{Me}-17$ were situated on the same face in $\mathbf{1}$, and these were assigned as $\beta$ protons, since the C-20 methyl is an $\alpha$-substituent at C-9. The $E$-configuration of C-1/10 double bond was elucidated from a correlation between $\mathrm{H}-1$ and $\mathrm{H}_{3}-20$. Based on the above findings, the main structure of 1 was elucidated unambiguously, and the chiarl carbons for 1 were assigned as $5 R^{*}, 8 S^{*}$, and $9 S^{*}$ although the configuration for 16-hydroxy group was not determined at this stage by this method.

Figure 3. The stereoview of $\mathbf{1}$ (generated from computer modeling) and the calculated distances $(\AA)$ between selected protons having key NOESY correlations.

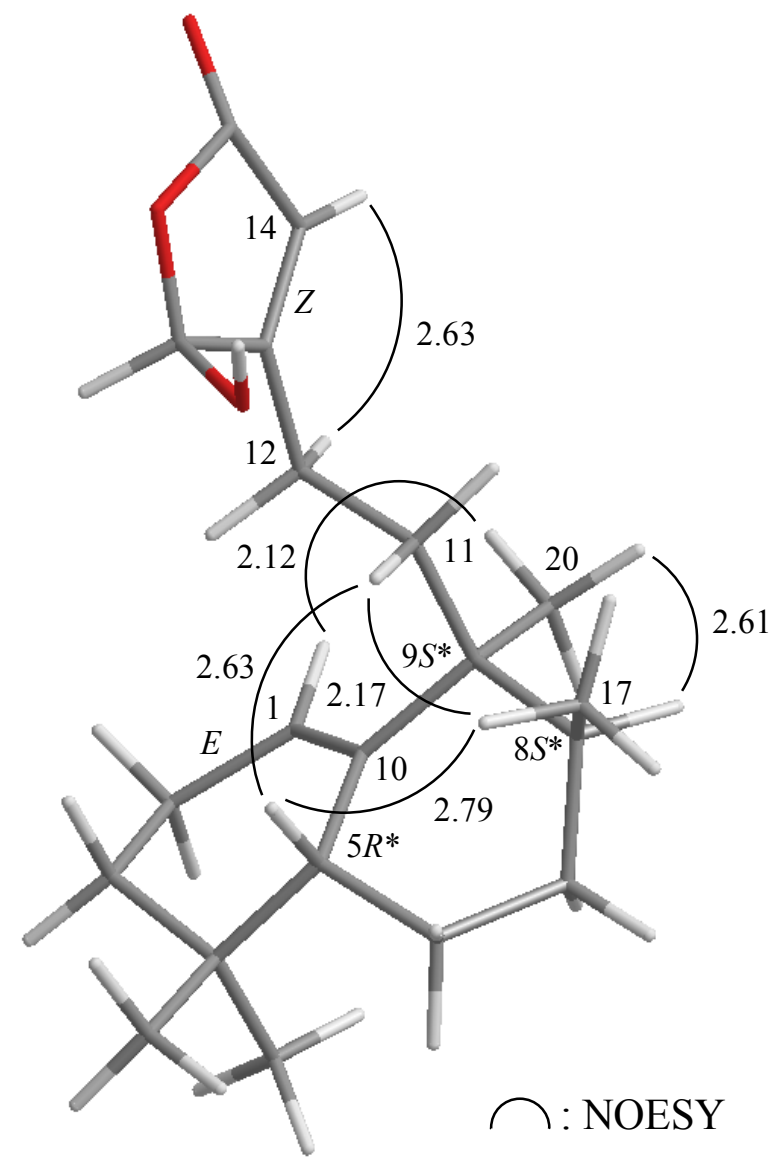


The cytotoxicity of diterpenoid 1 toward K562 (human erythromyeloblastoid leukemia), MOLT-4 (human acute lymphoblastic leukemia), HL-60 (human acute promyelocytic leukemia), DLD-1 (human colorectal adenocarcinoma), LoVo (human colorectal adenocarcinoma) and DU-145 (human prostate carcinoma) cells was studied, and the results were shown in Table 2. These data showed that echinohalimane A (1) exhibited cytotoxicity toward MOLT-4, HL-60, DLD-1 and LoVo cells. Furthermore, the in vitro anti-inflammatory effects of diterpenoid 1 were tested and echinohalimane A (1) displayed a significant inhibitory effect on the release of elastase by human neutrophils (Table 3).

Table 2. Cytotoxic data of diterpenoid 1.

\begin{tabular}{ccccccc}
\hline \multirow{2}{*}{ Compounds } & \multicolumn{6}{c}{ Cell lines IC 50 $(\boldsymbol{\mu g} / \mathbf{m L})$} \\
\cline { 2 - 7 } & K562 & MOLT-4 & HL-60 & DLD-1 & LoVo & DU-145 \\
\hline $\mathbf{1}$ & 6.292 & 2.111 & 2.117 & 0.967 & 0.563 & NA $^{\mathrm{b}}$ \\
Doxorubicin $^{\text {a }}$ & 0.171 & 0.001 & 0.048 & 2.322 & 0.959 & 0.005 \\
\hline
\end{tabular}

${ }^{\mathrm{a}}$ Doxorubicin was used as positive control; ${ }^{\mathrm{b}} \mathrm{NA}=$ not active at $20 \mu \mathrm{g} / \mathrm{mL}$.

Table 3. Inhibitory effects of diterpenoid 1 on the generation of superoxide anion and the release of elastase by human neutrophils in response to FMLP/CB.

\begin{tabular}{cccc}
\hline \multirow{2}{*}{ Compounds } & \multicolumn{2}{c}{ Superoxide anion } & Elastase release \\
\cline { 2 - 4 } & $\mathbf{I C}_{\mathbf{5 0}}(\boldsymbol{\mu \mathbf { g }} / \mathbf{m L})$ & $\mathbf{I n h}^{\mathbf{a}}$ & $\mathbf{I C}_{\mathbf{5 0}}(\boldsymbol{\mu \mathbf { g }} / \mathbf{m L} \mathbf{)}$ \\
\hline $\mathbf{1}$ & $>10$ & $20.55 \pm 5.18$ & $0.38 \pm 0.14$ \\
$\begin{array}{c}\text { DPI } \\
{ }^{\mathrm{b}}\end{array}$ & $0.80 \pm 0.21$ & & \\
Elastatinal $^{\mathrm{b}}$ & & & $31.95 \pm 5.92$ \\
\hline
\end{tabular}

${ }^{a}$ Percentage of inhibition (Inh\%) at a concentration of $10 \mu \mathrm{g} / \mathrm{mL} ;{ }^{b}$ DPI (diphenylene indonium) and elastatinal were used as positive control.

\section{Experimental Section}

\subsection{General Experimental Procedures}

Optical rotations were measured on a Jasco P-1010 digital polarimeter. Infrared spectra were recorded on a Varian Diglab FTS 1000 FT-IR spectrometer; peaks are reported in $\mathrm{cm}^{-1}$. NMR spectra were recorded on a Varian Inova 500 or a Varian Mercury Plus 400 NMR spectrometers using the residual $\mathrm{CHCl}_{3}$ signal $\left(\delta_{\mathrm{H}} 7.26 \mathrm{ppm}\right)$ as internal standard for ${ }^{1} \mathrm{H} \mathrm{NMR}$ and $\mathrm{CDCl}_{3}\left(\delta_{\mathrm{C}} 77.1 \mathrm{ppm}\right)$ for ${ }^{13} \mathrm{C}$ NMR. Coupling constants $(J)$ are given in Hz. ESIMS and HRESIMS were recorded by a Bruker APEX II mass spectrometer. Column chromatography was performed on silica gel (230-400 mesh, Merck, Darmstadt, Germany). TLC was carried out on precoated Kieselgel $60 \mathrm{~F}_{254}$ (0.25 mm, Merck); spots were visualized by spraying with $10 \% \mathrm{H}_{2} \mathrm{SO}_{4}$ solution followed by heating. HPLC was performed using a system comprised of a Hitachi L-7100 pump, a Hitachi L-7455 photodiode array detector and a Rheodyne injection port. A normal phase column (Hibar $250 \times 10 \mathrm{~mm}$, Merck, silica gel 60, $5 \mu \mathrm{m}$ ) was used for HPLC. 


\subsection{Animal Material}

Specimens of the gorgonian coral Echinomuricea sp. were collected by hand using scuba equipment off the coast of the southern Taiwan and stored in a freezer until extraction. This organism was identified by comparison with previous descriptions [8,9]. A voucher specimen (NMMBA-TW-GC-125) was deposited in the National Museum of Marine Biology and Aquarium, Taiwan.

\subsection{Extraction and Isolation}

The freeze-dried and minced material of Echinomuricea sp. (wet weight $1.68 \mathrm{~kg}$, dry weight $428 \mathrm{~g}$ ) was extracted with a mixture of methanol $(\mathrm{MeOH})$ and dichloromethane $\left(\mathrm{CH}_{2} \mathrm{Cl}_{2}\right)$ (1:1). The residue was partitioned with ethyl acetate (EtOAc) and $\mathrm{H}_{2} \mathrm{O}$. The EtOAc layer was partitioned between $\mathrm{MeOH}$ and $n$-hexane. The $n$-hexane layer was separated by silica gel and eluted using $n$-hexane/EtOAc/MeOH to yield 21 fractions $\mathrm{A}-\mathrm{U}$. Fraction $\mathrm{M}$ was separated on silica gel and eluted using a mixture of $n$-hexane/EtOAc to yield 10 fractions M1-M10. Fraction M3 was further purified by normal phase HPLC ( $n$-hexane/acetone, 10:1) to yield compound 1 (33.7 mg).

Echinohalimane A (1): yellowish oil; $[\alpha]_{\mathrm{D}}^{25}-102$ (c 1.69, $\left.\mathrm{CHCl}_{3}\right)$; IR (neat) $v_{\max } 3375,1755 \mathrm{~cm}^{-1} ;{ }^{1} \mathrm{H}$ $\left(\mathrm{CDCl}_{3}, 400 \mathrm{MHz}\right)$ and ${ }^{13} \mathrm{C}\left(\mathrm{CDCl}_{3}, 100 \mathrm{MHz}\right) \mathrm{NMR}$ data, see Table 1; ESIMS: $\mathrm{m} / z 341(\mathrm{M}+\mathrm{Na})^{+}$; HRESIMS: $m / z 341.2089$ (calcd for $\mathrm{C}_{15} \mathrm{H}_{18} \mathrm{O}_{4}+\mathrm{Na}, 341.2093$ ).

\subsection{Molecular Mechanics Calculations}

Implementation of the MM2 force field [7] in CHEM3D PRO software from CambridgeSoft Corporation (Cambridge, MA, USA; ver. 9.0, 2005) was used to calculate molecular models.

\subsection{Cytotoxic Assay}

The cytotoxicity of diterepnoid 1 was assayed with a modification of the 3-(4,5-dimethylthiazol-2yl)-2,5-diphenyltetrazolium bromide (MTT) colorimetric method according to previously described procedures $[10,11]$.

\subsection{Superoxide Anion Generation and Elastase Release by Human Neutrophils}

Human neutrophils were obtained by means of dextran sedimentation and Ficoll centrifugation. Measurements of superoxide anion generation and elastase release were carried out according to previously described procedures [12,13]. Briefly, superoxide anion production was assayed by monitoring the superoxide dismutase-inhibitable reduction of ferricytochrome $c$. Elastase release experiments were performed using MeO-Suc-Ala-Ala-Pro-Valp-nitroanilide as the elastase substrate.

\section{Conclusions}

In general, halimane-type diterpenoids exist in terrestrial plants, and are rarely found in marine organisms [14]. The compounds of this type were found to possess a carbon skeleton intermediate between that of labdanes and clerodanes $[15,16]$. It is worth noting that echinohalimane A (1) is the 
first halimane-type derivative isolated from marine organisms belonging to phylum Cnidaria. The study material Echinomuricea sp. has begun to be transplanted in culturing tanks with a flow-through sea water system located in the National Museum of Marine Biology and Aquarium, Taiwan, for the extraction of additional natural products in order to establish a stable supply of bioactive material.

\section{Acknowledgments}

This research was supported by grants from the National Museum of Marine Biology and Aquarium (Grant No. 100100101 and No. 100200311); the National Dong Hwa University; the Division of Marine Biotechnology, Asia-Pacific Ocean Research Center, National Sun Yat-sen University (Grant No. 00C-0302-05); and the National Science Council (Grant No. NSC 101-2325-B-291-001 and 101-2320-B-291-001-MY3), Taiwan, awarded to P.-J.S.

\section{References}

1. Molinski, T.F.; Dalisay, D.S.; Lievens, S.L.; Saludes, J.P. Drug development from marine natural products. Nat. Rev. Drug Discov. 2009, 8, 69-85.

2. Blunt, J.W.; Copp, B.R.; Keyzers, R.A.; Munro, M.H.G.; Prinsep, M.R. Marine natural products. Nat. Prod. Rep. 2012, 29, 144-222.

3. Berrue, F.; Kerr, R.G. Diterpenes from gorgonian corals. Nat. Prod. Rep. 2009, 26, 681-710.

4. Chung, H.-M.; Hwang, T.-L.; Wang, W.-H.; Fang, L.-S.; Sung, P.-J. Curcuphenol derivatives from the gorgonian Echinomuricea sp. Heterocycles 2009, 78, 2595-2600.

5. Chung, H.-M.; Hong, P.-H.; Su, J.-H.; Hwang, T.-L.; Lu, M.-C.; Fang, L.-S.; Wu, Y.-C.; Li, J.-J.; Chen, J.-J.; Wang, W.-H.; Sung, P.-J. Bioactive compounds from a gorgonian coral Echinomuricea sp. (Plexauridae). Mar. Drugs 2012, 10, 1169-1179.

6. Cheng, C.-H.; Chung, H.-M.; Hwang, T.-L.; Lu, M.-C.; Wen, Z.-H.; Kuo, Y.-H.; Wang, W.-H.; Sung, P.-J. Echinoclerodane A: A new bioactive clerodane-type diterpenoid from a gorgonian coral Echinomuricea sp. Molecules 2012, 17, 9443-9450.

7. Allinger, N.L. Conformational analysis. 130. MM2. A hydrocarbon force field utilizing $V_{1}$ and $V_{2}$ torsional terms. J. Am. Chem. Soc. 1977, 99, 8127-8134.

8. Bayer, F.M. Key to the genera of Octocorallia exclusive of Pennatulacea (Coelenterata: Anthozoa), with diagnoses of new taxa. Proc. Biol. Soc. Wash. 1981, 94, 902-947.

9. Fabricius, K.; Alderslade, P. Soft Corals and Sea Fans-A Comprehensive Guide to the Tropical Shallow-Water Genera of the Central-West Pacific, the Indian Ocean and the Red Sea, 1st ed.; Australian Institute of Marine Science: Queensland, Australia, 2001; pp. 59-60, 194-195.

10. Alley, M.C.; Scudiero, D.A.; Monks, A.; Hursey, M.L.; Czerwinski, M.J.; Fine, D.L.; Abbott, B.J.; Mayo, J.G.; Shoemaker, R.H.; Boyd, M.R. Feasibility of drug screening with panels of human tumor cell lines using a microculture tetrazolium assay. Cancer Res. 1988, 48, 589-601.

11. Scudiero, D.A.; Shoemaker, R.H.; Paul, K.D.; Monks, A.; Tierney, S.; Nofziger, T.H.; Currens, M.J.; Seniff, D.; Boyd, M.R. Evaluation of a soluble tetrazolium/formazan assay for cell growth and drug sensitivity in culture using human and other tumor cell lines. Cancer Res. 1988, $48,4827-4833$. 
12. Yu, H.-P.; Hsieh, P.-W.; Chang, Y.-J.; Chung, P.-J.; Kuo, L.-M.; Hwang, T.-L. 2-(2-Fluorobenzamido) benzoate ethyl ester (EFB-1) inhibits superoxide production by human neutrophils and attenuates hemorrhagic shock-induced organ dysfunction in rats. Free Radic. Biol. Med. 2011, 50, 1737-1748.

13. Hwang, T.-L.; Wang, C.-C.; Kuo, Y.-H.; Huang, H.-C.; Wu, Y.-C.; Kuo, L.-M.; Wu, Y.-H. The hederagenin saponin SMG-1 is a natural FMLP receptor inhibitor that suppresses human neutrophil activation. Biochem. Pharmacol. 2010, 80, 1190-1200.

14. Gavagnin, M.; Trivellone, E.; Castelluccio, F.; Cimino, G.; Cattaneo-Vietti, R. Glyceryl ester of a new halimane diterpenoic acid from the skin of the Antarctic nudibranch Austrodoris kerguelenensis. Tetrahedron Lett. 1995, 36, 7319-7322.

15. Hanson, J.R. Diterpenoids of terrestrial origin. Nat. Prod. Rep. 2011, 28, 1755-1772.

16. Silva, L.; Gomes, A.C.; Rodilla, J.M. Diterpene lactones with labdane, halimane and clerodane frameworks. Nat. Prod. Commun. 2011, 6, 497-504.

Samples Availability: Not available.

(C) 2012 by the authors; licensee MDPI, Basel, Switzerland. This article is an open access article distributed under the terms and conditions of the Creative Commons Attribution license (http://creativecommons.org/licenses/by/3.0/). 